\title{
Recent Publications
}

\section{BOOK REVIEWS}

Lancaster, F. Wilfrid, ed. Proceedings of the 1972 Clinic on Library Applications of Data Processing: Applications of OnLine Computers to Library Problems. University of Illinois, Graduate School of Library Science; London: Clive Bingley, $1972.169 \mathrm{p}$.

The papers presented at the ninth annual clinic represent a welcome continuation in this series. Reports and demonstrations were given on a wide range of library applications of on-line computers and reflected uses in libraries of various types and sizes. Examples of applications were given on a variety of jobs which cut across library operations from acquisitions, cataloging, and serials control to circulation systems and the retrieval of biomedical information.

The traditional conference scheme was followed by a keynote address (from a marketing representative), and a summation (from a network manager). Between these talks were sandwiched the reports on how things work at home. Some flavor was added to this clinic, however, with the talk by Ellsworth Mason entitled "Automation or Russian Roulette." Mason has tried to dissolve the smoke screen which has obfuscated the cost considerations in library automation, especially in on-line applications. His arguments are telling: library cost studies are not plentiful nor reliable, while careful comparisons of manual versus machine costs are virtually non-existent. Mason's part of the program was handled brilliantly in the summation by Glyn T. Evans, one of our most articulate spokesmen for networks. He said:

Mason is a brilliant performer. His enviable command of the language, his elegant turns of phrase, the dismissive wave of the hand, his unremitting rhetoric, bedazzle and bemuse us to our-and hisloss. For his supporters are hypnotized by the silken glitter of his top hat as he soft shoes his cane-twirling, spats-twinkling, white-spotlit way across the stage. And his opponents, infuriated and goaded, attack the shadow of his cape and not the substance of his argument (p. 158).
Evans goes on to deal specifically with Mason's points, and agrees that the cost/ benefit factor is the critical aspect of on-line application. In a clinic devoted to applications of on-line computers to library problems, one could expect to see a presentation on the largest and most predominant interactive system for shared cataloging-that of the Ohio College Library Center. Perhaps it was thought that OCLC has been represented sufficiently at meetings and in the literature.

The shared access to various data bases within a network organization is a problem of manifest administrative and technological concern. Although Pizer touches on this one area in dealing with "On-Line Technology in a Library Network," a fuller treatment of these questions somewhere in this work would have been welcomed.

Generally, each discussion of the individual application is clear, concise, and helpful. The clinic papers read like one of the few conferences about which one could say, "I wish I had been there."-Donald D. Hendricks, Director of the Library, The University of Texas Health Science Center, Dallas.

Burke, John Gordon, and Wilson, Carol Dugan. The Monthly Catalog of United States Government Publications; an Introduction to Its Use. Hamden, Conn.: Shoe String Press, 1973. \$6.50.

Don't buy this book. Unless you have $\$ 6.50$ to waste. Of the 113 pages in the book, approximately 36 are useful in terms of the stated purpose of the book. 36 is generous.

Chapter I contains four pages of original text describing the essential bibliographic elements which may be found in the Monthly Catalog. These pages are clear and well written and useful in helping someone who needs basic instruction. Accompanying these pages are three sample pages from the Monthly Catalog, one from the index, the second a typical page, and the third a sample order blank. The first two samples are quite useful as each bit of information is clearly identified; they illustrate the text 
well. Reproduction of the order blank is superfluous as there is one in each issue of the Monthly Catalog and the authors supply no explanatory information.

Chapter II is made up of three pages of text describing the indexing and features. These give very little help to the user. No mention is made of the fact that Monthly Catalog indexes are made up of key-words, subjects, issuing agencies and, since 1964, personal authors. Further, there is no mention of the two Decennial Cumulative Indexes, 1941-1950 and 1951-1960, unless these were mistakenly referred to as "decennial personal author indexes" by the authors. Omitted also is the fact that Monthly Catalog indexes list material under such headings as "atlases," "directories," and "ephemerides." The omissions noted are inexcusable as the information mentioned above is essential for effective and efficient use of the Monthly Catalog.

Chapter III, two pages of text, mentions additional sources for government publications: Government Reports Index, Bibliography of Agriculture, Index Medicus, Research in Education, and CIS Index, each with a short description of contents and use. Chapter IV describes in the same fashion sources for historical documentsGreely, Poore, Ames, the 1909 Checklist, and the Documents Catalog. Chapter V lists seven popular guides to the use of government publications, namely, Andriot, Boyd \& Rips, Leidy, O’Hara, Schmeckebier, Wisdom (Popular Names of U.S. Government Reports, 1966, which, incidently, was superseded in 1970 by a catalog with the same title by Bernier and David of the Library of Congress, LC 6.2:G74/970), and Wynkoop.

These five chapters take up 21 pages and contain the only useful information on using the Monthly Catalog.

The rest of the book is appendices. The first is a reproduction of the List of Classes of U.S. Government Publications Available for Selection by Depository Libraries (31 pages). Including this is akin to writing a pamphlet on how to use the card catalog and appending the LC class schedules. Appendix II is a short explanation of the SUDOCS classification scheme; Appendix III is an agency index to the classes. These two, without the List of Classes, are suff- cient for users of the Monthly Catalog.

Appendices IV and V have to do with depository library laws and practices which may or may not help the user. Appendix VI is an incredible 34-page reproduction of the "List of Depository Libraries" as of September 1971. Anyone having need for this guide is presumably using the Monthly Catalog, and could easily turn to the September issue and get the latest list.

My advice to the prospective buyer is "Wait till it comes out in paperback," hopefully with the appendices omitted, and a bright, attractive cover saying "How to Use the Monthly Catalog." You could drill a hole in it, tie a string through the hole, and hang it next to the Monthly Catalog where it could really be used. ERIC has such a guide for twenty-five cents, AEC distributes their Guide to Nuclear Science Abstracts free.-Joyce Ball, University of Nevada, Reno.

Becker, Joseph, and Pulsifer, Josephine S. Application of Computer Technology to Library Processes: A Syllabus. Metuchen, N.J.: Scarecrow Press, 1973. 173 p. $\$ 5.00$.

In 1970 James Kortendick and Elizabeth W. Stone reported on the results of a research project entitled "Post-Master's Education for Middle and Upper-Level Personnel in Libraries and Information Centers." One of the educational needs they identified through a sample survey of federal librarians was the need for a post-master's course in library automation. Using data elicited in the sample survey and a systems approach to curriculum development, Becker and Pulsifer have prepared an outline for such a post-master's course, which they present in this syllabus.

The course is divided into eight units of study: a general introduction, computer technology, systems analysis, the MARC program, library clerical processes, reference and SDI services, related technologies, and library networks. Each unit includes a discussion of behavioral objectives for the unit, an outline of the topics covered, a course syllabus, and a bibliography. A list of general sources of information and an additional bibliography comprise the remainder of the work. There is no index, but the introductory outline to each unit facili- 